This article has been retracted: please see INNOVATIONS in pharmacy retraction policy (https://pubs.lib.umn.edu/index.php/innovations/policies). This article has been retracted by the Editor and Publisher due to the inappropriate use of previously published work. 


\title{
Patient Safety: A Deep Concern to Caregivers
}

AK Mohiuddin, Assistant Professor

Department of Pharmacy, World University of Bangladesh, Bangladesh

\begin{abstract}
Patient safety is a global concern and is the most important domains of health-care quality. Medical error is a major patient safety concern, causing increase in health-care cost due to mortality, morbidity, or prolonged hospital stay. A definition for patient safety has emerged from the health care quality movement that is equally abstract, with various approaches to the more concrete essential components. Patient safety was defined by the IOM as "the prevention of harm to patients." Emphasis is placed on the system of care delivery that prevents errors; learns from the errors that do occur; and is built on a culture of safety that involves health care professionals, organizations, and patients. Patient safety culture is a complex phenomenon. Patient safety culture assessments, required by international accreditation organizations, allow healthcare organizations to obtain a clear view of the patient safety aspects requiring urgent attention, identify the strengths and weaknesses of their safety culture, are giving units identify their existing patient safety problems, and benchmark their scores with other hospitals.
\end{abstract}

Keywords: Commercialism; Medication Error; Prescription; Nurse; Patient; Healthcar

Abbreviations: Institute for HealthCare Consumerism's (IHC); Institute of Med in (IOM); Ind nt Reporting Systems (IRS); Third Next available Appointment (TNA); Wait Time to Consultation (WTC); Sound-Alike/Look-A re Drugs (SALAD); Swiss Emergency Triage Scale (SETS); Hepatitis C virus (HCV); Hospital-acquired pneumonia (HA hruman Deh boment Index HDI); Global Antimicrobial Surveillance System (GLASS); Antimicrobial Resistance (AMR); Multidr g-Resistap (MDR); Emergency Department (ED); Fabry disease (FD); Attention deficit hyperactivity disorder (ADHD); Alzheimer's dis se (AD); ccine-Preventable Diseases (VPDs); Health literacy $(\mathrm{HL})$; American College of Clinical Pharmacists (ACCP); American Society Healt System Pharmacists (ASHP); Clinical Pathways (CPs); Medication Non-Adherence (MNA)

\section{Introduction}

Since patient safety was first brought to studies have shown a staggering numbe of . tients hal hed by preventable medical errors. Thes errors ind systems failures, human factors, complica dechnologies, powerful drugs, prolonged hospital stays, d co cutting measures, to name a few. Medical errors can serioy injury or death and result in billions of ollan in en nealth care costs nationwide each year. 40 est hates that one out of every 10 patients worldwide are th cted by these errors. Death may not quite be the final cure fo 'ife's ills that Socrates imagined. Recent safety issues imposed by healthcare providers are merely medication safety, provider patient ratio, length of physician consultation, medical supply shortages, quality reporting, antibiotic resistance, sepsis, unnecessary emergency hospitalizations, poor diagnosis, wrong prescribing and treatment etc. A good health system aims to deliver the best possible care to the individual patient while at the same

Corresponding author: AK Mohiuddin, Assistant Professor Department of Pharmacy

World University of Bangladesh, Bangladesh

151/8, Green Road, Dhanmondi, Dhaka - 1205, Bangladesh

Email: trymohi@gmail.com; Phone: +8801716477485 time being responsive to the health needs of the entire population it serves. For many health systems worldwide, resources are an important limitation. Commercialism and profit orientation in medicine are an important cost driver. Similar controversies exist with regard to improvements in quality and fairness of healthcare delivery. It is increasingly hard to find areas of life into which commercialism has not encroached. The corrosive effects of advertising and commercialization are more damaging because of the ways modern societies have come to rely on physicians, and are often made less healthy in the process. Here it is important to remember that commercial forces not only respond to markets, but work diligently to create markets. A prime example is pharmaceutical advertising to the public. Drug advertisements influence patients to ask their physicians about drugs that have been promoted.

\section{Commercialism in Healthcare Service}

Healthcare Commercialism is defined by the IHC Forum as, "transforming an employer's health benefit plan into one that puts economic purchasing power-and decision-making-in the hands of participants. This is best achieved by supplying employees with the decision-making information and support tools they need, along with financial incentives, rewards, and other benefits that encourage personal involvement in altering 
health and health care purchasing behaviors. Commercialism in health care is an application of operating and managing principles typically found in business and commerce (financial incentivizing, profit-making, competition, marketing/advertising, and focus on the bottom line) to health care delivery. The US health care system ranks the highest on commercialism among Western industrialized democracies. Commercialism poses a threat to medical professionalism, patient care, and even the integrity of science, which is a foundation of our trust in medicine and medical professionalism. This is a timely topic that is getting some attention in the bioethics and medical literature. The idea of the profit motive in healthcare and the impact that it has on the professional practice of nurses and physicians should be thoroughly judged. The public healthcare systems have always had various weaknesses, which the capitalist media have relentlessly exploited. A private healthcare sector is nearly always active alongside the public system, providing parallel provision for those who can pay cherry-picking profitable services, offering 'hotel' style hospital accommodation, short waiting times for treatment - i.e. in general offering a model of a commodified service that looks attractive precisely because it is expensive. However, the most important common factor in the success of capital's drive to convert state-funded health care into a profit-making commodity has undoubtedly been the wider hegemony of neoliberalism, both as a system of social practices and as a system of ideas. Germany for example, private hospitals treat patients who are older on average and who have more serious health co than those in public hospitals. The data also private for-profit hospitals are better equ difficult cases and more complex pathologi larger proportion of beds in these hospi emergency room and intensive care pat

\section{Medication Safety}

Close to 6,800 prescription med. tir s and puntless overthe-counter drugs are ava in Ur States. It is estimated that in 2019,25 bil on reta, orescriptions will be filled throughout the Un ed complicate a practitioner's responsibl during patient care, there are thousands of health supplems ts, herbs, potions, and lotions used by the public regularly to treat their health problems [7]. Each year, in the United States alone, 7,000 to 9,000 people die as a result of a medication error. The total cost of looking after patients with medication-associated errors exceeds $\$ 40$ billion each year [8]. The underlined causes are many distractions, distortion, illegible writing, over/under dosing, SALAD, wrong metric measures, error induced kidney/liver dysfunction, wrong duration, use of abbreviations, supplement overload, wrong indication or direction, negligence, prescribing high risk medications etc. [9-13]. The cost of medication errors worldwide has been estimated as US\$42 billion/year [14, 15]. Doctors in US incorrectly prescribe antibiotics in nearly a third of cases. Study finds more than half of US population receives prescription annually and estimates 'inappropriate' prescriptions in doctor's office setting at up to $30 \%$ [16]. NHS medication errors raise fears thousands could be dying because of 237 million mistakes every Year, some 237 million errors are made annually [17]. In India, studies done in Uttarakhand and Karnataka have documented ME rate to be as high as $25.7 \%$ and $15.34 \%$, respectively, in hospitalized patients.

\section{Nurse/Patient Ratio}

Despite progress in the healthcare industry toward achieving goals, nurse managers and administrators working on hospital units continue to struggle with knowing what constitutes the right number and quality of nurses matched to patients' needs to achieve clinical outcome targets. Consider that in 2016, $62.2 \%$ of the country's 2 millio nurses worked in hospitals with a median pay of 68,450 pe year [18]. With salaries making up nearly $b$ ' ' ' hosp of 'Als' expenses and nursing comprising abo $30 \%$ of sa rir effective management of nursing resour s, in ding staring, is imperative for meeting financial 0 com Higher Murse staffing and richer skill mix are as ted wit iroved patient outcomes [19]. In addition, no ves provide up to $80 \%$ of primary healthcare. dissatisto wion with the nursing care may indicate poor nealthcare quality and decreases the achievement of standards 20].

\section{Lelrom.of Physician Consultation}

-mary care-driven health systems are effective at reducing disease, mortality and promoting a more equitable distribution of health worldwide. As the global population increases, the demand for primary care is also growing in both economically developed, low-income, middle-income countries. This is leading to an array of different consultation lengths, with concerns among primary care physicians worldwide about the impact of shorter consultations [21, 22]. Average consultation length is also used in the primary care monitoring tool as an outcome indicator [23]. Consultation length is affected by the number of topics discussed with the patient; Consultation length often varies from one country to another and is determined by both patient's and doctor's characteristics; can be attributed to GP, patient and practice characteristics. While Deveugele et al. found that a longer consultation length was linked to females and older age. Howie et al. further discuss the issue of less attention being given to psychosocial issues in consultations [24, 25]. In USA the average consultation length has increased steadily to over 20 min [26], more than 15 min in Canada [27] and less than 15 minutes in Australia [28]. Comparing this, terrible found in Hongkong and Afghanistan (around $3 \mathrm{~min}$ ), in China and India (2 min) and less than $1 \mathrm{~min}$ in Bangladesh [29-33].

\section{High WTC}

Waiting is a common phenomenon in the doctor's waiting room. High number of patients, shortage of staff and aging equipment are among the factors contributing to a lengthy waiting time. At the emergency department (ED), prolonged 
wait times have been found to be associated with increased morbidity and mortality, and decreased patient satisfaction [34]. Although delays in care delivery are common-and unpleasant-occurrences in both public and private health care systems, there are few reliable data with which to determine the prevalence, degree, or nature of the problem. Patient waiting time in hospital emergency to receive the first treatment step was 66 min in Australia [35], 45 min in USA [36], 50 min Iran [37] and 64 min Turkey [38]. According to SETS, care to be initiated in life-threatening emergencies (receiving immediate care), urgent conditions (to be seen within 20 minutes) [39].

\section{Shortage of Physicians}

The world health organization predicts that the world needs an additional 10 million health care workers by 2030 [40]. Between 2000 and 2030, the number of people in the United States over the age of 65 was expected to double. This elderly population makes twice as many physician visits as those under 65 [41]. More hospital staff along with physicians will be required with population growth. Interestingly, South Asian countries are lack of hospitals comparing to that. Nearly $86 \%$ of all the medical visit in India are made by rurales with majority still travelling more than $100 \mathrm{~km}$ to avail health care facility of which $70-80 \%$ is born out of pocket landing them in poverty. Government succeeded in generating infrastructures in urban area but fail to do so in rural, sustaining $70 \%$ of India, population [42]. However, The Times of India claims healthy doctor-patient ratio, 1:921 [43, 44], which is much wer reported in Nepal (2.28 doctors, nurses, and mi vives )er 1000 population) [45], worst in rural Bangladesh people) [46].

\section{Shortage of Hospital Supply}

Drug shortages have become all to common al affect all aspects of the health care deli cry sy $\mathrm{cm}$. The increased number of drug shortages has negative impact on patient care as well as cost implions. Shortages of critical drugs such chen thera agents, analgesics, injectable nutritional sup anesthetics, antiinfectives, and cardiovascul agents are common [47-50]. The impact of drug shortages is yltifaceted, with over $50 \%$ of health care practitioners believing that shortages have influenced practice and resulted in inferior patient care [51]. A Canadian study relayed anesthesiologists' opinion that drug shortages were responsible for prolonged recovery times, delayed surgical procedure scheduling, and increased recovery cost. Nearly half of them (49\%) felt shortages were the impetus for the administration of inferior anesthetics. Drug shortages often impact vulnerable populations including cancer patients or neonates, for whom few, if any, equivalent alternatives exist; shortages may result in clinical complications, as exemplified by selenium shortages. Drug shortages may also force practitioners to prescribe infrequently used medications and concentrations, which can lead to medication errors as demonstrated with prior fentanyl shortages. Drug shortages have also impacted life outside of patient care; for example, a planned execution in Oklahoma was delayed due to a drug shortage [52].

\section{Quality Reporting by Hospital Staffs}

IRSs are and will continue to be an important influence on improving patient safety. However, they are not the panacea that many believe them to be. They have several limitations that should be considered. Most of these limitations stem from inherent biases of voluntary reporting systems. These limitations include: i) IRS can't be used to measure safety (error rates); ii) IRS can't be used to compare organizations; iii) IRS can't be used to measure changes over time; iv) IRS generate too many reports-w) IRS often don't generate in-

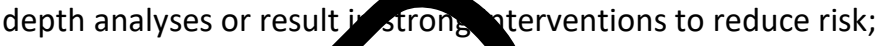
vi) IRS are associated vo costs. IR do offer significant value; their value is foup in th follow g: i) IRS can be used to identify local sy em hazards, ij s can be used to aggregate experiences fo unco mon conditions; iii) IRS can be used to share less is wh and Coss organizations; iv) IRS can be used $t$ crease $A$ rir safety culture. Moving forward, severur stra oies are suggested to maximize their value: i) reporting asier; ii) make reporting meaningful to the reporter; jii) make the measure of success system changes, rather th events reported; iv) prioritize which events to port an investigate, report and investigate them well; v) comme with diverse stakeholders to enhance the value of IRS $-57]$.

\section{Access to Healthcare}

According to the National Rural Hospital Association, "Currently one in three rural hospitals is in financial risk. At the current rate of closure, $25 \%$ of all rural hospitals will close within less than a decade in USA." [58] A relatively similar situation found in China. Chinese patients often choose to directly access higher level hospitals, thus bypassing primary care facilities. As a result, higher level hospitals are overcrowded, while primary care facilities remain underutilized [59]. Conversely, poor housing condition, unsafe drinking water, lack of sanitation, use of biomass fuels, exposure to environmental odds as a part of the livelihood among the marginal population group often increase the risk of numerous health problems in India. Twelve percent of critically ill patients remain untreated in the less developed villages [60]. According to WHO, 5.9 million children under 5 years of age died in 2015, with a global under-five mortality rate of 42.5 per 1000 live births. Levels of child mortality are higher in developing countries. Moreover, leading causes of child death in the post-neonatal period were pneumonia, diarrhea, injuries and malaria [61].

\section{Hospital Acquired Sepsis}

Astonishingly, it seems that healthcare access and HCV prevalence are related in Pakistan; it is estimated that $70 \%$ of new HCV infections in Pakistan are attributed to routine medical procedures. Particularly concerning are infections 
caused by contaminated syringes, which are so prevalent in the healthcare settings. Villages are gripped by fear; no one knew whose life would be taken next by the deadly virus [62]. Nosocomial infections, otherwise known as hospital-acquired infections, are those infections acquired in hospital or healthcare service unit that first appear $48 \mathrm{~h}$ or more after hospital admission or within 30 days after discharge following in patient care. HAP is the second most common nosocomial infection, and is the most common hospital infection leading to death in critically ill patients [63]. European acute care hospitals estimated the prevalence of healthcare-associated infections to be $6 \%$; of these, UTI was the third most common infection (19\%). Based on this, the annual health burden of hospitalized patients with UTI was estimated to be 81.2 disability-adjusted life years per 100000 individuals in the general population [64]. Healthcare-associated infections occur in both adult and pediatric patients. Bloodstream infections, followed by pneumonia and urinary tract infections are the most infections in children, urinary tract infections are the most common healthcare - associated infections in adults [65]

\section{Availability of Essential Drugs}

Worldwide, many countries have developed a list of essential medicines for children to improve prescribing. The WHO recommends that each country evaluate and adapt the list in order to create a list of essential medicines that is appropriat for its own environment. Specialty drugs are administered to less than $1 \%$ to $2 \%$ of the US population, yet they ac $38 \%$ of US prescription drug costs. By 2018, US Sp costs are expected to account for $50 \%$ of all drug costs [66]. In China, access to essent children is hampered by low availability. that at least one-third of the world's por regular access to essential medicin countries, Korea was a country available than other countries [

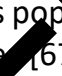
has esth ted tty $u g$ and price of 32 medicines ron six low- and middle-income countrie (Bang desh, azil, Malawi, Nepal, Pakistan and Sri Lank co cromat improvement of governance and managem t efficiency, and assessing local supply options, may improve yailability of essential drugs. Prices could be reduced by improving purchasing efficiency, eliminating taxes and regulating mark-ups [69]. In Canada, there is no list or central source of information related to safety, efficacy and tolerability of medication forms and formulations for children [70] and we cannot think of its existence in south Asian countries.

\section{High Prices of Drugs and Health Services}

Retail prescription drug spending in the US has been estimated at over US\$340 billion annually, with projected growth to nearly US\$600 billion by 2025 , accounting for more than $10 \%$ of total healthcare spending in the US [71, 72]. High costs of new drugs and price increases for existing products have brought criticism and political interest in the drug pricing debate over rising drug prices as well as cost effectiveness and affordability [73-76]. Drug price transparency has been argued as a potential solution to improve affordability within the US and abroad as it would improve the negotiating position for purchasers around the world [77]. According to a March 2017 Bloomberg article, "in the U.S., \$15 of every \$100 spent on brand-name drugs goes to middlemen...[and] the largest share, about $\$ 8$, goes to benefit managers" [78]. Patients are the central figures in any healthcare system, and although they are often the victim of misaligned incentives, they also bear some responsibility for rising costs. Typically, patients are motivated to spend as little as possible out of pocket. India is the world's largest democracy, with an independent media and strong civil society. However, India ranks 130 on 2018 out of 189 countries HDI [79/ of their monthly incom on healtho re in India [60].

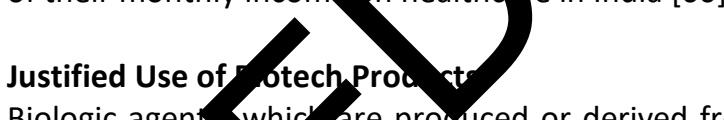

Biologic agen whic are prouruced or derived from a living organism the st rap y growing class of specialty drugs, and ho romise to ationize the management of a range of crronic redical conditions [80, 81]. The challenge, brer, is red ciling the potential therapeutic benefit with the high cost of these agents. Specialty drugs contribute significan to the inpatient diagnosis-related group payment stem, ten with unproved benefits over less-expensive thempres. These medications often may be more appropriate initiation in the ambulatory setting, after the mechanism of payment for continued therapy has been established. As healthcare costs rise and reimbursements decrease, healthcare organization leadership and clinical providers must collaborate to provide high-value healthcare. Medications are a key driver of the increasing cost of healthcare, largely as a result of the proliferation of expensive specialty drugs, including biologic agents. Loosely defined based on their high costs, the need for special handling protocols, and close patient monitoring, specialty drugs are projected to account for $50 \%$ of the total medical expenditure by 2019 [82].

\section{Antibiotic Resistance}

Antibiotic treatment is one of the main approaches of modern medicine, which is used to combat infections. The "golden era" of antibiotics ranged from the 1930s to 1960s, which gave rise to many antibiotics [83]. In 2018, GLASS reveals widespread occurrence of antibiotic resistance among 500000 people with suspected bacterial infections across 22 countries. The most commonly reported resistant bacteria were Escherichia coli, Klebsiella pneumoniae, Staphylococcus aureus, and Streptococcus pneumoniae, followed by Salmonella spp. "Some of the world's most common - and potentially most dangerous - infections are proving drug-resistant," -as stated by the director of WHO's Antimicrobial Resistance Secretariat [83]. AMR poses a serious global threat of growing concern to human, animal, and environment health. This is due to the emergence, spread, and persistence of MDR bacteria or "superbugs." MDR bacteria exist across the animal, human, 
and environment triangle or niche and there is interlinked sharing of these pathogens in this triad. The plausible causes of "the global resistome" or AMR include excessive use of antibiotics in animals (food, pets, aquatic) and humans, antibiotics sold over-the-counter, increased international travel, poor sanitation/hygiene, and release of nonmetabolized antibiotics or their residues into the environment through manure/feces. These factors contribute to genetic selection pressure for the emergence of MDR bacterial infections in the community. Recently, the global consumption of antimicrobials in livestock has indicated the hotspots of antibiotics use across the continents that will have economic and public health impacts in the years to come. In food animals, antibiotics are commonly used in cattle, chicken, and pigs and it is projected that in 2030 such use will increase up to $67 \%$ in the most populated countries of the world. Furthermore, as many antibiotics are often inappropriately prescribed, a more personalized approach based on precise diagnosis tools will ensure that proper treatments can be promptly applied leading to more targeted and effective therapies. However, in more general terms, also the overall use and release of antibiotics in the environment needs to be better controlled [84-87].

\section{Unnecessary Emergency Hospitalizations}

As concern grows in most countries over increasing health care costs, more attention is focused on reducing waste an unnecessary services. Reducing avoidable emergency department (ED) visits is an important health syste pal. Around $15 \%$ of ED visits end in inpatient admission 08,89 A significant number of 'avoidable' ED visits repor Hospital Ambulatory Medical Care Survey for mental health and dental conditions, fully equipped to treat [90]. In th Medicare \& Medicaid Services ha Implemento the first financial penalties on hospitals or exc sive readmissions. Attention likely will be inc sis dimeted to all hospitalizations because dms ons epresent only approximately $9 \%$ of ho $\mathrm{rtal}$ ac hission and to avoidable ED visits because of the ex nse care in this setting and its tendency to lead tu unscheduled hospital admissions [91]. Because some visits are reventable, they may indicate poor care management, inadequate access to care, or poor choices on the part of patients. ED visits for conditions that are preventable or treatable with appropriate primary care lower health system efficiency and raise costs. An estimated $13 \%$ to $27 \%$ of ED visits in the United States could be managed in physician offices, clinics, and urgent care centers, saving \$4.4 billion annually [92-94].

\section{Poor Health Diagnosis}

Both clinicians and patients rely on an accurate diagnostic process to identify the correct illness and craft a treatment plan. Achieving improved diagnostic accuracy also fulfills organizational fiscal, safety, and legal objectives. 'Improving Diagnosis in Health Care', report by Institute of Medicine in the
USA concluded that most people will likely experience a diagnostic error in their lifetime [95]. Every nine minutes, a patient in a U.S. hospital dies because a diagnosis was wrong or delayed -- resulting in 80,000 deaths a year [96]. Terms such as overdiagnosis, underdiagnosis and undiagnosed are now frequently used, but their relationship to diagnostic error remains undefined [97]. Some research suggests that $40 \%$ of people in the vegetative state are misdiagnosed [98]. Because the clinical features of FD overlap with those of other disorders, errors and delays in diagnosis are common [99]. Despite being an extensively studied condition, the causes of ADHD remain poorly understood and substantial in children, controversy exists regarding its correct diagnosis [100]. In a retrospective analysis of clinical trials, 63\% of deceased patients who were clinir als osed with $A D$ while alive were found to have $A D$ th other $p$ thology [101]. The rate of misdiagnosis of $\mathrm{p}$ cents vith bir lar receiving outpatient treatment was quite high they often received a misdiagnosis depr sion [102]. Laryngeal edema has been associated with nortali rate of $12-40 \%$, and in many undiagr as cases, ry history and recurrent skin and abdominal racks since childhood could have informed the tiagnos [103].

\section{Wrong Di pensing}

ispensir errors occur in clinical and community pharmacy anu-nmonly involve supply of the wrong drug, the wrong - $n$ ngth and the wrong form of medication [104, 105]. They occur at an average rate of 4 in 250 prescriptions (1.6\%) in pharmacies in the United States [106], and incidences up to $45 \%$ have been reported in different pharmacy settings [107]. A study in the Netherlands showed that $41 \%$ of all medication incidents in community pharmacies related to information technology, were about choosing the wrong drug. One third of incidents were associated with confusion of similar drug names and nearly half were associated with drug strength confusion [108]. Drug strength confusion can happen when two strengths of the same drug look alike, e.g. $3.75 \mathrm{mg}$ and $0.375 \mathrm{mg}$ pramipexole [109]. Drug name and strength confusion are serious issues as they are preventable errors with potential detrimental impact on clinical practice and patient safety $[110,111]$.

\section{Lack of Therapeutic Guideline Implementation}

Research indicates that clinical guidelines are often not applied. The success of their implementation depends on the consideration of a variety of barriers and the use of adequate strategies to overcome them. Despite the growing number of guidelines, their use in practice is frequently reported as being unpredictable, often slow and complex. It is estimated that about $30 \%-40 \%$ of patients receive treatment that is not based on scientific evidence, and $20 \%-25 \%$ receive treatments that are either not needed or potentially harmful $[112,113]$. Guideline adaptation has been defined as a systematic approach to modify and contextualize evidence-based guidelines to suit implementation in the local healthcare 
system. The process provides an opportunity to systematically consider transferability of recommendations across different settings, including variation in needs, values, costs, and availability of resources [114]. In India, clinical guidelines, also called standard treatment guidelines (STGs), are developed at the national and state levels and by a wide range of agencies. However, the quality of these guidelines is uncertain [115].

\section{Poor Vaccination}

Of the nearly 10 million children who die each year before reaching their fifth birthday, WHO (World Health Organization) estimates that 2.5 million die from diseases that could be prevented with currently available or new vaccines [116]. However, in the United States it is estimated that 40,00080,000 people die annually from VPDs, while hundreds of thousands more are hospitalized. The majority of cases and $99 \%$ of the deaths from VPDs are in older adults [117]. Yet, people continue to challenge the evidence and refuse vaccinations in many parts of the world. Vaccine hesitancy is the refusal of people to take vaccines or a delay in vaccine acceptance despite vaccination offers from health authorities. This behavioral phenomenon is context- and vaccine-specific. $\mathrm{HL}$ is independently associated with several undesirable health outcomes, including poorer overall health status, hospitalization, mortality, and healthcare costs [118]. The Philippine dengue vaccination is the only mass dengue vaccination to date with more than 800,000 individual vaccinated. Vaccination controversy due to perceived increased risk of serious dengue illness and death media associating the vaccine program to corruption has caused low vaccine acceptability Healthcare was found to be manufacturi (Estrogen receptor antagonist), a drug tha in India nor elsewhere [120]. Point supplied rancid Vitamin $A$ capsy

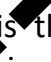
in Banglao sh which caused sickness (experiencing vo rting hsation and feeling unwell) in children of Chittagong, sazaar $x^{\prime}$ Lakhimpur among other places of Ban $h$, b in 13 [121].

\section{Pharmacists Role}

Medication errors are col non in community pharmacies. Safety culture is considered a ctor for medication safety but has not been measured in this setting. Both the discovery and reporting of medication errors can be improved by creating an environment where consultation about medication regimes are promoted between members of a network and with pharmacists. Understanding the safety culture of community pharmacies can help identify areas of strength and those that require improvement [122]. Standardized patient safety course should be considered in the curriculum for junior pharmacy students to improve their attitude toward patient safety. The World Health Organization (WHO) has also introduced an inclusive patient safety curriculum [123]. With the shifting role of community pharmacists towards patient education and counselling, they are well-positioned to conduct a post-discharge home visit which could prevent or solve drug- related problems [124]. Close attention to patient safety associates with lowered incidences of adverse events in hospitals. Pharmacists are well positioned to facilitate the inpatient care and discharge process by performing medication reconciliation, identifying patients with poor health literacy or non-adherence, and providing tailored discharge counselling [125]. Both the ACCP and ASHP have identified CPs as tools for pharmacists to provide cost-effective patient care plans, integrate pharmaceutical services, institutional culture, and partake leadership position in the development and implementation of the multifaceted pharmaceutical care [126]. Pharmacists have the unique education and training to identify MNA events early, as well as developing strategies to mitigate or resolve MNA related issues [126-130]. Pharmacists are not alone in their que cor po ent safety and quality care. Still their role is sic ficant in patient-care and safety measurement.

\section{Conclusion}

The exper tion the he care system is better care for patient re that $s^{+}$dards-based and outcomes-driven. This expecto ion is founded on the dual principle that every t deserv to be safe and every patient deserves optimal medication therapy. Community pharmacists most frequently initiated actical issues, but explored patients' medication oliefs le adequately. Inadequate patient counselling during thenusition is a contributing factor. They must adapt their momunication to address the wide variety of patients' drugrelated problems during these home visits and achieve patient-centered communication. It imparts increased patients' satisfaction, better recall of information and improved health outcomes and requires active participation of both the pharmacist and the patient. Patients should be encouraged to express their needs and concerns regarding their medication, which pharmacists should address to support patients in making informed decisions. It is important to discuss patient experiences, beliefs and adherence issues pro-actively, since not all patients might express these issues themselves. In pharmaceutical treatments, a unique pattern of social network in each healthcare setting can steer behaviors within organizations towards risk reduction in such environments. Gaining insight in the communication during these home visits could be valuable for optimizing these visits; and consequently, to improve patient safety at readmission to primary care.

\section{Reference}

1. Gavin Brookes and Kevin Harvey, Opening up the NHS to market, Journal of Language and Politics, 15, 3, (288), (2016).

2. Roy A. Health Care and the Profit Motive. National Affairs · Spring 2010. Available From: https://www.nationalaffairs.com/publications/detail/h ealth-care-and-the-profit-motive 
3. Labrie Y. The Positive Role of Profit in the Field of Health Care. Economic Note. Montreal Economic Institute November 2014 Health Care Series. Available From: http://www.iedm.org/files/note1014_en.pdf

4. APhA. The Issue Of Profit In Health Care. Policy Statement Database Jan 01 1997, Policy Number 9716(PP).

5. The IHC Forum. What is health care consumerism? www.theihccforum.com/about-the-forum/. Accessed January 22, 2018.

6. Statista. Total number of retail prescriptions filled annually in the United States from 2013 to 2024 (in billions)*. Pharmaceutical Products \& Market. (C) Statista 2018. Available From: https://www.statista.com/statistics/261303/totalnumber-of-retail-prescriptions-filled-annually-in-theus/

7. Bock LW. Mixing herbal and is pepprescription meds. Clinical Feature, Clinical Advisor June 13, 2012. Available From: https://www.clinicaladvisor.com/features/mixingherbal-and-prescription-meds/article/245427/

8. Bhimji SS, Scherbak Y. Medication Errors. [Updated 2018 Oct 27]. In: StatPearls [Internet]. Treasure Island (FL): StatPearls Publishing; 2018 Jan-.

9. Naunton M, Gardiner HR, Kyle G. Look-alike, soundalike medication errors: a novel case concerning a Slow$\mathrm{Na}$, Slow-K prescribing error. Int Med Case Rep J. 2015;8:51-3. Published 2015 Feb 16. doi:10.2147/IMCRJ.S78637

10. Yang $P$, Chen N, Wang RR, Li L, Jiang SP. Inappropriateness of medication prescrip chronic kidney disease patients withou in a Chinese tertiary teaching hospit Manag. 2016;12:1517-1524. Publi ect 16 Oct 1) doi:10.2147/TCRM.S116789

11. de Oliveira AV, Rocha FT, Ab cu SR. Acute In failure and self-medication. Arq as Cir g. 2014;27(4):294-7.

12. SHAPIRO Law Group. Med. ti Errors 30 Years' Experience Fightin cal valige From: https://w' w.shar rolawg w.com/malpracticemedication-er

13. J.K. Aronson; Med ion errors: what they are, how they happen, and hoh $\mathrm{Q}$ avoid them, QJM: An International Journal of Medicine, Volume 102, Issue 8, 1 August 2009, Pages 513-521, https://doi.org/10.1093/qjmed/hcp052

14. Assiri GA, Shebl NA, Mahmoud MA, et al. What is the epidemiology of medication errors, error-related adverse events and risk factors for errors in adults managed in community care contexts? A systematic review of the international literature. BMJ Open. 2018;8(5):e019101. Published 2018 May 5. doi:10.1136/bmjopen-2017-019101

15. Fujita K, Moles RJ, Chen TF. Quality indicators for responsible use of medicines: a systematic review. BMJ Open. 2018;8(7):e020437. Published 2018 Jul 16. doi:10.1136/bmjopen-2017-020437
16. Jessica G. Doctors in US incorrectly prescribe antibiotics in nearly a third of cases The Guardian May, 032016

17. Huffpost. UK NHS Medication Errors Raise Fears Thousands Could Be Dying Because Of $237 \mathrm{~m}$ Mistakes Every Year Some 237 million errors are made annually February 23, 2018

18. Paulsen RA. Taking nurse staffing research to the unit level. Nurs Manage. 2018;49(7):42-48.

19. Fagerström L, Kinnunen M, Saarela J. Nursing workload, patient safety incidents and mortality: an observational study from Finland. BMJ Open. 2018;8(4):e016367. Published 2018 Apr 24. doi:10.1136/bmjopen-2017016367

20. Sharew NT, Bizuneh HT, Assefa HK, Habtewold TD. Investigating admittatients' satisfaction with nursing care at $D$,ore Ben $n$ Referral Hospital in Ethiopia: a cros rectional s dy. BMJ Open. 2018;8(5). 2110. Publish 2018 May 17. doi:10/36/bmiope, 20/-021107

21. Starfi $B, S /$, Macinko J. Contribution of primary c. to th syste is and health. Milbank $Q$ 05;83:45, 50 doi:10.1111/j.146800 2005.00409.x

Wilso. McDonald P, Hayes L, et al. Longer booking intervalsun general practice: effects on doctors' stress \& d arousal. Br J Gen Pract 1991;41:184-7.

23. ngos D, Boerma W, Bourgueil Y, et al. The strength of primary care in Europe: an international comparative study. Br J Gen Pract 2013;63:742-50.

doi:10.3399/bjgp13X674422

24. Lemon $\mathrm{TI}$, Smith RH. Consultation Content not Consultation Length Improves Patient Satisfaction. J Family Med Prim Care. 2014;3(4):333-9.

25. Ahmad BA, Khairatul K, Farnaza A. An assessment of patient waiting and consultation time in a primary healthcare clinic. Malays Fam Physician. 2017;12(1):1421. Published 2017 Apr 30.

26. NAMCS/NHAMCS - About the Ambulatory Health Care Surveys. https://www.cdc.gov/nchs/ahcd/index.htm (accessed 6 July 2017).

27. Stewart M, Brown JB, Weston WW. Patient-Centred Interviewing Part III: Five Provocative Questions. Can Fam physician Médecin Fam Can 1989;35:159-61.

28. Australian GP Statistics and Classification Centre. General practice activity in Australia 2006-07, 2006

29. Fry J. Hong Kong: Need for improvement in primary care. Lancet 1990;336:558 doi:10.1016/01406736(90)92104-P

30. Afghanistan Medicine Use Study: A Survey of 28 Health Facilities in 5 Provinces, 2009.

31. Jin G, Zhao Y, Chen C, et al. The length and content of general practice consultation in two Urban districts of Beijing: a preliminary observation study. PLoS One 2015;10:e0135121 doi:10.1371/journal.pone.0135121 [PMC free article] [PubMed] [Ref list]

32. Sarwal R. Reforming Central Government Health Scheme into a 'Universal Health Coverage'model. Natl Med J INDIA 2015. 
33. Guyon AB, Barman A, Ahmed JU, et al. A baseline survey on use of drugs at the primary health care level in Bangladesh *. Bull World Health Organ 1994;72:26571.

34. Shen Y, Lee LH. Improving the wait time to consultation at the emergency department. BMJ Open Qual. 2018;7(1):e000131. Published 2018 Jan 3. doi:10.1136/bmjoq-2017-000131

35. Li L, Georgiou A, Vecellio E, Eigenstetter A, Toouli G, Wilson R. et al. The Effect of Laboratory Testing on Emergency Department Length of Stay: A Multihospital Longitudinal Study Applying a Cross-classified Randomeffect Modeling Approach. Acad Emerg Med. 2015;22(1):38-46.

36. Howanitz P, Steindel S, Cembrowski G, Long T. Emergency department stat test turnaround times $A$ College of American Pathologists' Q-Probes study for potassium and hemoglobin. Arch Pathol Lab Med. 1992;116:122-8.

37. Fazl Hashemi SME, Sarabi Asiabar A, Rezapour A, Azami-Aghdash S, Hosseini Amnab H, Mirabedini SA. Patient waiting time in hospital emergency departments of Iran: A systematic review and metaanalysis. Med J Islam Repub Iran. 2017;31:79. Published 2017 Dec 14. doi:10.14196/mjiri.31.79

38. Erenler AK, Akbulut S, Guzel M, et al. Reasons for Overcrowding in the Emergency Department: Experiences and Suggestions of an Education and Research Hospital. Turk J Emerg Med. 2016;14(2):5963. Published 2016 Feb 26. doi:10.5505/1304.7361.2014.48802

39. Grosgurin O, Cramer B, Schaller M, Sarasi Rutschmann OT. Patients leaving the e department without being seen by retrospective database analysis. Dec 6;143:w13889. doi: 10.441 eCollection 2013. PubMed
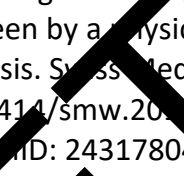
Yysician. Wkly. 13

0. World Health Organizatic Healt Norkforce 2030: towards a global strategy o han resurces for health, 2015; Avail http://www.wh 295Strategy_Re_rt- $/$ 5.pdf?ua_1.

41. Institute of Medich (US) National Cancer Policy Forum. Ensuring Qual Cancer Care through the Oncology Workforce: Sustaining Care in the 21st Century: Workshop Summary. Washington (DC): National Academies Press (US); 2009. Supply and Demand in the Health Care Workforce.

42. Singh S, Badaya S. Health care in rural India: A lack between need and feed. South Asian J Cancer. 2014;3(2):143-4.

43. Tiwari R, Negandhi H, Zodpey SP. Health Management Workforce for India in 2030. Front Public Health. 2018;6:227. Published 2018 Aug 20. doi:10.3389/fpubh.2018.00227

44. Rao S. With 1:921, India has healthy doctor-patient ratio. The Times of India Apr 3, 2018
45. World Health Organization. Working together for health. The World Health Report 2006. Geneva: World Health Organization; 2006.

46. Joarder T, Rawal LB, Ahmed SM, Uddin A, Evans TG. Retaining Doctors in Rural Bangladesh: A Policy Analysis. Int J Health Policy Manag. 2018;7(9):847-858. Published 2018 May 5. doi:10.15171/ijhpm.2018.37

47. McBride A, Holle LM, Westendorf C, et al. National survey on the effect of oncology drug shortages on cancer care. Am J Health Syst Pharm. 2013;70:609-617.

48. Mendez MN, Gibbs L, Jacobs RA, et al. Impact of a pipercillin-tazobactam shortage on antimicrobial prescribing and the rate of vancomycin resistant enterococci and Clostridium difficile infections. Pharmacotherapy. 20م-26:61-67.

49. Pluss-Suard C, P- natier $A$ quffieux $C$, et al. Changes in the use of broa spectrum tibiotics after cefepime shortage: ame s ies anal is. Antimicrob Agents Chemot er. 2012;56. $90,94$.

50. Hall K, ryso $a$, Flowerdew G, et al. Drug shortages in c. adial esthes A national survey. Can J Anaesth. 213;60:53 55 Ba ver AM, Cark AM, Witmer DR, et al. National surve, the impact of drug shortages in acute care hospitals. Am J Health Syst Pharm. 2004;61:2015-2022.

52. Uulder CR, Mehta B, Bookstaver PB, Sims LD, evenson B. Impact of Drug Shortages on Health system Pharmacies in the Southeastern United States. Hosp Pharm. 2015;50(4):279-86.

53. Stavropoulou C, Doherty C, Tosey P. How Effective Are Incident-Reporting Systems for Improving Patient Safety? A Systematic Literature Review. Milbank Q. 2015;93(4):826-66.

54. Pham JC, Girard T, Pronovost PJ. What to do with healthcare incident reporting systems. J Public Health Res. 2013;2(3):e27. Published 2013 Dec 1. doi:10.4081/jphr.2013.e27

55. Ramírez E, Martín A, Villán Y, et al. Effectiveness and limitations of an incident-reporting system analyzed by local clinical safety leaders in a tertiary hospital: Prospective evaluation through real-time observations of patient safety incidents. Medicine (Baltimore). 2018;97(38):e12509.

56. Klemp K, Zwart D, Hansen J, et al. A safety incident reporting system for primary care. A systematic literature review and consensus procedure by the LINNEAUS collaboration on patient safety in primary care. Eur J Gen Pract. 2015;21 Suppl(sup1):39-44.

57. Anja H. Brunsveld-Reinders, M. Sesmu Arbous, Rien De Vos, Evert De Jonge; Incident and error reporting systems in intensive care: a systematic review of the literature, International Journal for Quality in Health Care, Volume 28, Issue 1, 1 February 2016, Pages 2-13, https://doi.org/10.1093/intahc/mzv100

58. National Rural Hospital Association. Medicare cuts hurt rural America.

www.ruralhealthweb.org/advocate/medicare-cutshurt-rural. Accessed September 7, 2017 
59. Liu Y, Zhong L, Yuan S, van de Klundert J. Why patients prefer high-level healthcare facilities: a qualitative study using focus groups in rural and urban China. BMJ Glob Health. 2018;3(5):e000854. Published 2018 Sep 19. doi:10.1136/bmjgh-2018-000854

60. Barik D, Thorat A. Issues of Unequal Access to Public Health in India. Front Public Health. 2015;3:245. Published 2015 Oct 27. doi:10.3389/fpubh.2015.00245

61. World Health Organization. World Health Statistics 2016: Monitoring Health for the Sustainable Development Goals (SDGs) World Health Organization, 2016. [Ref list]

62. Alaei K, Sarwar M, Juan SC, Alaei A. Healthcare and the Preventable Silent Killer: The Growing Epidemic of Hepatitis C in Pakistan. Hepat Mon. 2016;16(11):e41262. Published 2016 Oct 15. doi:10.5812/hepatmon.41262

63. Frantzeskaki F, Orfanos SE. Treating nosocomial pneumonia: what's new. ERJ Open Res. 2018;4(2):00058-2018. Published 2018 Jun 26. doi:10.1183/23120541.00058-2018

64. Vallejo-Torres L, Pujol M, Shaw E, et al. Cost of hospitalised patients due to complicated urinary tract infections: a retrospective observational study in countries with high prevalence of multidrug-resistant Gram-negative bacteria: the COMBACTE-MAGNET, RESCUING study. BMJ Open. 2018;8(4):e020251. Published 2018 Apr 12. doi:10.1136/bmjopen-2017020251

65. Revelas A. Healthcare - associated infections: A public health problem. Niger Med J. 2012;53(2):59-6

66. Express Scripts. Express Scripts 2015 Drug $T$ ind Report. March 2016. Available From: http://lab.express-scripts.com/lab/d report/ /media/e2c9d19240e94fo, 706e1300 50. $\underline{\operatorname{ash} x}$

67. Sun $X$, Wei J, Yao Y, et al. Ay ability, prices d affordability of essential edicine chor children: a crosssectional survey in Jiangsu 'ce, Chra. BMJ Open. 2018;8(10):e02364 Jishe 2018 ct 18. doi:10.1136/bm pen-2 8-023،

68. Kwon HY, Kim K Fod rilability and Affordability of Dru With a Conditional Approval by the European Medicl Agency; Comparison of Korea With Other Countries and the Implications. Front Pharmacol. 2018;9:938. Published 2018 Sep 3. doi:10.3389/fphar.2018.00938

69. Mendis S, Fukino K, Cameron A, et al. The availability and affordability of selected essential medicines for chronic diseases in six low- and middle-income countries. Bull World Health Organ. 2007;85(4):279-88.

70. Woods H, Oronsaye E, Bali A, et al. Development of a provisional essential medicines list for children in Canada: consensus process. CMAJ Open. 2018;6(1):E146-E150.
71. Martin AB, Hartman $M$, Washington $B$, Catlin A, National Health Expenditure Accounts Team National Health Spending: faster growth in 2015 , as coverage expands and utilization increases. Health Aff. 2017;2017(36):166-176. doi: 10.1377/hlthaff.2016.1330.

72. Keehan SP, Stone DA, Poisal JA, Cuckler GA, Sisko AM, Smith SD, et al. National health expenditure projections, 2016-25: price increases, aging push sector to $20 \%$ of economy. Health Aff. 2017;36:553-563. doi: 10.1377/hlthaff.2016.1627.

73. Ward JW, Mermin JH. Simple, effective, but out of reach? Public health implications of HCV drugs. N Engl J Med. 2015;373:2678-2680. doi: 10.1056/NEJMe151202-

74. Hirsch BR, Balu s chulmo KA. The impact of specialty pharmaceuticar s drivers $d$ health care costs. Health Aff. 2014; 7 1714 720. dg 10.137

75. Chhar J J, K iwal F, Ruberts MSMS, Dunn MAMA. Ci-efte deness d budget impact of hepatitis $C$ us treath ith sofosbuvir and ledipasvir in the Un d States. Ann Intern Med. 2015;162:397-406. doi: 10.73. VM14-1336

76. Kantarjian H, Rajkumar SV. Why are cancer drugs so pensive in the United States, and what are the lutions? Mayo Clin Proc. 2015;90:500-504. doi: 0.1016/j.mayocp.2015.01.014.

77. Vogler S, Paterson KR. can price transparency contribute to more affordable patient access to medicines? Pharmacoecon Open. 2017;1:145-147. doi: 10.1007/s41669-017-0028-1.

78. Weinberg N, Langreth R. Drug costs too high? Fire the middleman. Bloomberg Businessweek. March 3, 2017. Available From:

www.bloomberg.com/news/articles/2017-03-03/drugcosts-too-high-fire-the-middleman. Accessed September 10, 2017

79. UNDP India. India ranks 130 on 2018 Human Development Index. Posted on September 14, 2018.

80. Wu N, Lee YC, Shah N, Harrison DJ. Cost of biologics per treated patient across immune-mediated inflammatory disease indications in a pharmacy benefit management setting: a retrospective cohort study. Clin Ther. 2014;36:1231-1241, 1241.e1-1241.e3

81. Glover L. Why are biologic drugs so costly? U.S. News \& World Report. February 6, 2015.

http://health.usnews.com/health-news/healthwellness/articles/2015/02/06/why-are-biologic-drugsso-costly. Accessed February 17, 2017.

82. Durvasula R, Kelly J, Schleyer A, Anawalt BD, Somani S, Dellit TH. Standardized Review and Approval Process for High-Cost Medication Use Promotes Value-Based Care in a Large Academic Medical System. Am Health Drug Benefits. 2018;11(2):65-73.

83. High levels of antibiotic resistance found worldwide, new data shows. Saudi Med J. 2018;39(4):430-431. 
84. Aslam B, Wang W, Arshad MI, et al. Antibiotic resistance: a rundown of a global crisis. Infect Drug Resist. 2018;11:1645-1658. Published 2018 Oct 10. doi:10.2147/IDR.S173867

85. Medina E, Pieper DH. Tackling Threats and Future Problems of Multidrug-Resistant Bacteria. Curr Top Microbiol Immunol. 2016;398:3-33. doi: 10.1007/82_2016_492. Review. PubMed PMID: 27406189.

86. Martens E, Demain AL. The antibiotic resistance crisis, with a focus on the United States. J Antibiot (Tokyo). 2017 May;70(5):520-526. doi: 10.1038/ja.2017.30. Epub 2017 Mar 1. Review. PubMed PMID: 28246379.

87. Lázár V, Martins A, Spohn R, Daruka L, Grézal G, Fekete G, Számel M, Jangir PK, Kintses B, Csörgő B, Nyerges Á, Györkei Á, Kincses A, Dér A, Walter FR, Deli MA, Urbán E, Hegedǔs Z, Olajos G, Méhi O, Bálint B, Nagy I, Martinek TA, Papp B, Pál C. Antibiotic-resistant bacteria show widespread collateral sensitivity to antimicrobial peptides. Nat Microbiol. 2018 Jun;3(6):718-731. doi: 10.1038/s41564-018-0164-0. Epub 2018 May 24. PubMed PMID: 29795541.

88. Greenwald PW, Estevez RM, Clark S, Stern ME, Rosen T, Flomenbaum N. The ED as the primary source of hospital admission for older (but not younger) adults. Am J Emerg Med. 2016;34:943-947.

89. Morganti-Gonzalez K, Baufman S, Blanchard J, et al. The Evolving Role of Emergency Departments in the United States. RR 280-ACEP. RAND. Available From: http://www.rand.org/pubs/research_reports/RR280.ht ml. Published 2013.

90. Hsia RY, Niedzwiecki M. Avoidable emerge department visits: a starting point. Int J Care. 2017 Oct 1;29(5):642-645. doi: 10.1093/intqhc/mzx081. PubMed

91. Solberg LI, Ohnsorg KA, Parker FD, et al. tentially Preventable Hospital and Ey rgency Depar ent Events: Lessons from a L s Inn ation Project. Perm J. 2018;22:17-102.

92. Dowd B, Karmarken wens $T$, energency department util ation a a meas of physician performance. A V M 214;29(2):135-43.

93. Enard KR, Ganelin Reducing preventable emergency departme utilization and costs by using community health workers as patient navigators. J Healthc Manag 2013;58(6);412-28.

94. Weinick RM, Burns RM, Mehrotra A. How many emergency department visits could be managed at urgent care centers and retail clinics? Health Aff 2010;29(9):1630-6.

95. Committee on Diagnostic Error in Health Care, Board on Health Care Services, Institute of Medicine, The National Academies of Sciences, Engineering, and Medicine; Balogh EP, Miller BT, Ball JR, editors. Improving Diagnosis in Health Care. Washington (DC): National Academies Press (US); 2015 Dec 29. PubMed PMID: 26803862.

96. UPI Trending. Incorrect diagnoses responsible for 80,000 deaths per year. Health News Sept. 20, 2018
97. Newman-Toker DE. A unified conceptual model for diagnostic errors: underdiagnosis, overdiagnosis, and misdiagnosis. Diagnosis (Berl). 2014;1(1):43-48.

98. Wade DT. How often is the diagnosis of the permanent vegetative state incorrect? A review of the evidence. Eur J Neurol. 2018 Apr;25(4):619-625. doi: 10.1111/ene.13572. Epub 2018 Feb 16. Review. PubMed PMID: 29338107.

99. Colomba P, Zizzo C, Alessandro R, et al. Fabry disease and multiple sclerosis misdiagnosis: the role of family history and neurological signs. Oncotarget. 2018;9(8):7758-7762. Published 2018 Jan 5. doi:10.18632/oncotarget.23970

100. Ford-Jones PC. Misdiagnosis of attention deficit hyperactivity disord Normal behaviour' and relative maturity. Paedia Child th th. 2015;20(4):200-2.

101. Gaugler JE, Asc r-Svanum Roth DL, Fafowora T, Siderowf seach $\$$. Char teristics of patients misdiag osed yith $A$, er's disease and their medic ion y an analysis of the NACC-UDS database. " 2013. Sel137. Published 2013 Dec 19. i:10.1186, 47 2318-13-137

2. Sh $\mathrm{H}$, Zhangl, Xu C, Zhu J, Chen M, Fang Y. Analysis of MA agnosis of Bipolar Disorder in An Outpatient Setting. Jnanghai Arch Psychiatry. 2018;30(2):93-101.

103. Pldovan D, Bara N, Nădășan V, Gábos G, Mihály E. nsequences of Misdiagnosed and Mismanaged Aereditary Angioedema Laryngeal Attacks: An Overview of Cases from the Romanian Registry. Case Rep Emerg Med. 2018;2018:6363787. Published 2018 Oct 22. doi:10.1155/2018/6363787

104. James KL, Barlow D, McArtney R, Hiom S, Roberts D, Whittlesea $C$. Incidence, type and causes of dispensing errors: a review of the literature. Int J Pharm Pract. 2009;17: 9-30. doi: 10.1211/ijpp/17.1.0004

105. Galanter WL, Bryson ML, Falck S, Rosenfield R, Laragh $\mathrm{M}$, Shrestha $\mathrm{N}$, et al. Indication alerts intercept drug name confusion errors during computerized entry of medication orders. PLoS One. 2014;9: 3-9. doi: 10.1371/journal.pone.0101977

106. Flynn EA, Barker KN, Carnahan BJ. National observational study of prescription dispensing accuracy and safety in 50 pharmacies. J Am Pharm Assoc. 2003;43: 191-200. doi: 10.1331/108658003321480731

107. Cheung KC, Bouvy ML, De Smet PAGM. Medication errors: The importance of safe dispensing. Br J Clin Pharmacol. 2009;67: 676-680. doi: 10.1111/j.13652125.2009.03428.x

108. Cheung K-C, van der Veen W, Bouvy ML, Wensing $M$, van den Bemt PMLA, de Smet PAGM. Classification of medication incidents associated with information technology. J Am Med Inform Assoc. 2014;21: e63-70. doi: 10.1136/amiajnl-2013-001818

109. Anto B, Barlow D, Oborne CA, Whittlesea C. Incorrect drug selection at the point of dispensing: A study of potential predisposing factors. Int J Pharm Pract. 2011;19: 51-60. doi: 10.1111/j.2042-7174.2010.00072. 
110. Emmerton LM, Rizk MFS. Look-alike and sound-alike medicines: Risks and "solutions". Int J Clin Pharm. 2012;34: 4-8. doi: 10.1007/s11096-011-9595-x

111. Ostini R, Roughead EE, Kirkpatrick CMJ, Monteith GR, Tett SE. Quality Use of Medicines-Medication safety issues in naming; Look-alike, sound-alike medicine names. Int J Pharm Pract. 2012;20: 349-357. doi: 10.1111/j.2042-7174.2012.00210.x

112. Fischer F, Lange K, Klose K, Greiner W, Kraemer A. Barriers and Strategies in Guideline Implementation-A Scoping Review. Healthcare (Basel). 2016;4(3):36. Published 2016 Jun 29. doi:10.3390/healthcare4030036

113. Rauh S, Arnold D, Braga S, et al. Challenge of implementing clinical practice guidelines. Getting ESMO's guidelines even closer to the bedside: introducing the ESMO Practising Oncologists' checklists and knowledge and practice questions. ESMO Open. 2018;3(5):e000385. Published 2018 Jul 25. doi:10.1136/esmoopen-2018-000385

114. Mehndiratta A, Sharma S, Gupta NP, Sankar MJ, Cluzeau F. Adapting clinical guidelines in India-a pragmatic approach. BMJ. 2017;359:j5147. Published 2017 Nov 17. doi:10.1136/bmj.j5147

115. Sonawane DB, Karvande SS, Cluzeau FA, Chavan SA, Mistry NF. Appraisal of maternity management and family planning guidelines using the agree II instrument in India. Indian J Public Health 2015;59:264-71. doi:10.4103/0019-557X.169651 pmid:26584165

116. Lob-Levyt J. Vaccines for the poor. An interview with Julian Lob-Levyt. Bull World Health Organ. 2008;86(6):427-8.

117. Doherty TM, Connolly MP, Del Giudice G, Vaccination programs for older adults demographic change. Eur Geriatr Me 2018;9 289300.

118. Lorini C, Santomauro F, Donzellini M, et a Health literacy and vaccination: A s lematic revieh yum Vaccin Immunother. 2017 4(2):4 -488.

119. Valido EM, Laksanawati IS, to A. Ac eptability of the dengue vaccina mon waren un poor communities of cuezon ity, $\mathrm{Ph}$, sines before and after vaccine su. ensi Notes. 2018;11(1):661. Pu. shed 2018 Sep 10. doi:10.1186/s13104-o -3766-y

120. Thacher T. Olive Healthcare faces legal action over violations Olive Healthcare was found to be manufacturing enclomiphene, a drug that is approved neither in India nor elsewhere. Livemint. Apr 042018.
121. Jahan N, Hossain MA, Hossain A, Amran MS. Review on Pharmacovigilance Practice for Safety of Medication System in Bangladesh. Bangladesh Pharmaceutical Journal 20(1): 105-114, 2017

122. Aboneh EA, Stone JA, Lester CA, Chui MA. Evaluation of Patient Safety Culture in Community Pharmacies. J

Patient Saf. 2017 Nov 4. doi: 10.1097/PTS.0000000000000245. PubMed PMID: 29112024.

123. Walton M, Woodward H, Van Staalduinen S, et al. The WHO patient safety curriculum guide for medical schools. Qual Saf Health Care. 2010;19(6):542-546.

124. Ensing HT, Vervloet $M$, van Dooren AA, Bouvy ML, Koster ES. Patient-pharmacist communication during a post-discharge pharmist home visit. Int J Clin Pharm. 2018;40(3):712

125. Haynes KT, Ob e A, Cawt In C, Kripalani S. Pharmacis recol nendat hs to improve care transiti s. Anp Phan her. 2012;46(9):1152-9.

126. Ismah Osm i M, Aburezz R, Alhamdan H, Quadri K $\mathrm{A}$. Ph acists Anterprofessional Collaborators d Leader $\mathrm{hr}$ gh Clinical Pathways. Pharmacy (Bo. ). 2018;0,1):24. Published 2018 Mar 16. doi:10 390/pharmacy6010024

127. Oswald . Non-adherence: medicine's weakest link. The

armaceutical Journal February 08, 2018.

128. ven A, Arnet I. How pharmacists can encourage patient adherence to medicines. The Pharmaceutical Journal August 01, 2018.

129. El-Rachidi S, LaRochelle JM, Morgan JA. Pharmacists and Pediatric Medication Adherence: Bridging the Gap. Hosp Pharm. 2017;52(2):124-131.

130. McDonough PR. Identifying and resolving medication nonadherence. APhA PharmacyToday February 2015Volume 21, Issue 2, Page 44. 